\title{
REGIME PECULIAR DAS ORGANIZAÇÕES SOCIAIS E O INDISPENSÁVEL APERFEIÇOAMENTO DO MODELO FEDERAL
}

\author{
JUAREZ FREITAS*
}

1. Introdução; 2. O instituto das organizações sociais. Regime peculiar: pessoas juridicas de direito privado, sem finalidade lucrativa, não-integrantes da Administração Pública indireta e submetidas a princípios juspublicistas; 3. Sugestões para o aprimoramento do modelo federal; 4. Principais conclusões.

\section{Introdução}

O sistema normativo deve, antes de tudo, servir para coibir o vício e promover a solidariedade. Em semelhante linha, não há como sermos refratários a formas jurídicas novas, nos exatos limites em que se prestarem a tais funções superiores. Com esta observação inicial, forçoso asseverar que, com as devidas cautelas, as organizações sociais podem desempenhar papel precioso de colmatação de lacunas da ação estatal. Todavia, não devem agir de maneira substitutiva ou excludente. Em face da eleição desta premissa maior, focalizamos as organizações sociais como alternativas tendencialmente úteis, a serem, sem maniqueísmo, encartadas no terceiro setor (nem estatal, nem exclusivamente privado), com a indispensável prudência. Nesta ótica, aliás, a disciplina normativa, no plano dos Estados e Municípios, não deve reprisar imprecisões e defeitos da legislação federal. Com ênfase, sobretudo, há de ser evitado o ensejo para possíveis desvios no sentido de uma operacionalização do instituto como forma de privatização dissimulada ou despida das imperativas precauções.

Destarte, adotando prisma crítico em relação ao modelo federal, porém reconhecendo, até por motivos empíricos, os insofismáveis méritos potenciais do instituto em tela (por exemplo, na vitalíssima área da saúde), é que se encaminham as considerações que seguem.

* Professor de Direito Administrativo da UFRGS e do Mestrado em Direito da PUC-RS.

R. Dir. Adm.

Rio de Janeiro, 214: 99-106, out./dez. 1998 
2. O instituto das organizaçōes sociais. Regime peculiar: pessoas jurídicas de direito privado, sem finalidade lucrativa, näo-integrantes da Administração Pública indireta e submetidas a princípios juspublicistas

No âmbito federal, a Lei 9.637/98 apresentou, com alguma imprecisão, os aspectos conducentes à conceituação das organizações sociais. Apenas refere que o Poder Executivo poderá (numa censurável abertura excessiva à discrição) qualificar como tais as pessoas jurídicas de direito privado (associações civis e fundações) que, sem fins lucrativos, desempenharem determinadas atividades arroladas no referido diploma (ensino, pesquisa científica, desenvolvimento tecnológico, preservação do meio ambiente, cultura e saúde) e observarem os requisitos específicos elencados no art. $2^{\mathrm{Q}}$ (registro do ato constitutivo com todos os elementos ali constantes $\mathrm{e}-$ noutro perigoso excesso de submissão a parâmetros políticos - aprovação, quanto à conveniência ou à oportunidade, de sua qualificação, pelo titular de órgão supervisor ou regulador da área de atividade e do Ministro da Administração Federal e da Reforma do Estado). Em outras palavras, as organizações sociais ocupam zona mesclada, intermediária entre o público e o privado, claramente integrantes do emergente e valiosíssimo terceiro setor. Convém notar, ainda, que estas entidades ocupam lugar característico que as diferenciam das demais organizações da sociedade civil de caráter público, porquanto a "publicização" do regime aparece em maior escala, embora não sejam catalogáveis como pessoas jurídicas integrantes da estrutura da Administração Pública Federal indireta. De qualquer sorte, sob pena de tautologia, não é adequado pensá-las apenas como pessoas jurídicas de direito privado designadas como tais, uma vez que preencham determinados requisitos. Além de lacunosa, esta definição se arrima, bem de ver, na incompreensão de fundo do próprio regime misto e na excessiva discricionariedade no tocante à habilitação, somente menos grave do que aquela destinada à desqualificação (nos termos do art. 16: "O Poder Executivo poderá proceder à desqualificação da entidade como organização social, quando constatado o descumprimento das disposições contidas no contrato de gestão"). Ora, sobremaneira neste último caso, mostra-se incontornável dever - nunca uma mera faculdade - , efetuar a desqualificação, revelando-se manifesto o lapso na opção efetuada pelo legislador, que preferiu, no ponto, uma politização exacerbada do regime de tais organizações, quiçá visando a acelerar o processo de privatização, paradoxalmente publicizando uma parcela do terceiro setor, como se vê no art. 20 do diploma em tela, tema que será retomado no tópico terceiro deste estudo.

Com efeito, o regime das organizações sociais desponta como atípico. Não atuam por delegação nos moldes de concessionárias ou permissionárias de serviços públicos, tampouco podem almejar finalidade lucrativa. Logo, não executam serviços públicos nos moldes do art. 175 da Constituição Federal, mas recebem delegação (a "qualificação" do art. $2^{2}$ da Lei 9.637/98). De outra parte, estão obrigadas a outorgar ampla publicidade de seus atos, comprometendo-se com o cidadão-cliente e podem receber recursos humanos públicos (com ônus para origem), assim como permissão de uso de bens públicos. Não integram a Administração Pública indireta e se prestam a absorver atividades desenvolvidas por entidades públicas extintas por lei específica. 
Ainda: representantes do Poder Público devem, sob pena de não-qualificação, participar do Conselho de Administração. Decididamente, obedecem a um regime "sui generis", não-estatal, porém certamente dominado por regras de direito privado e princípios de direito público (útil a distinção de Robert Alexy in Theorie der Grundrechte, Suhrkamp, 1994, pp. 71-154. A calhar convém ter presente a observação de Hartmut Maurer in Allgemeines Verwaltungsrecht. München, C.H. Beck'sche Verlag, 1985, $\S 3^{\circ}, 3,9$, p. $25-27$, quando põe em realce que a administração publica apenas se utiliza das formas do direito privado, mas não da liberdade ou da autonomia no sentido privatista. Lembrando a conhecida expressão de Hans J. Wolff (in Verwaltungsrecht. München, C.H. Becksche Verlag, 1974, § 23, pp. 104-112), Maurer deixa claro que, no "direito administrativo privado" ("Verwaltungsprivatrecht"), se de um lado há conexão, de outro, há dominância do direito público sobre o direito privado: "Der Verwaltung stehen nur die privatrechtlichen Rechtsformen, nicht die Freiheiten und Möglichkeiten der Privatautonomie zu. Man spricht daher in diesem Zusammenhang von Verwaltungsprivatrecht (Wolff): Es ist das öffentlich-rechtlich überlagerte und gebundene Privatrecht, das der Verwaltung bei der Wahrnehmung von Verwaltungsaufgaben zur Verfügung steht" (in ob. cit., p. 26). Tal dominância de princípios públicos, não de regras, parece dever existir também fora da estrutura formal da Administração).

No intuito de robustecer as assertivas anteriores, urge destacarmos os traços peculiares do regime de tais pessoas jurídicas de direito privado, integrantes do terceiro setor. Ei-los:

(a) os objetivos das organizações sociais devem ter relevância (em realidade, prestam serviço público "lato sensu" ou, para evitarmos querelas terminológicas desnecessárias, serviços de relevância pública, em que pese o fato de serem prestados por pessoas privadas (art. $2^{\mathrm{Q}}, \mathrm{I}$, “a”);

(b) a finalidade das mesmas deve ser não-lucrativa, razão pela qual seus excedentes deverão, forçosamente, ser reinvestidos em suas atividades sociais (art. $2^{\varrho}, I$, "b"), vedada a distribuição de bens ou de parcela do patrimônio líquido (art. 2o, $\mathrm{I}$, "h");

(c) devem respeitar a previsão de participação, no órgão colegiado de deliberação superior, de representantes do Poder Público, sendo, na órbita federal, de vinte a quarenta por cento de membros natos no Conselho de Administração (arts. $2^{o}$, I, " $d$ " e 30, I, "a"), regra que, malgrado sua boa intenção, não deve ser imitada à risca pelos legisladores estaduais e municipais, pois o referido Conselho é que deve aprovar o contrato de gestão da entidade (art. $4^{\circ}$, II), sendo este celebrado entre o Poder Público e a entidade qualificada, donde segue a recomendação de evitar uma relação possivelmente não-isenta das partes;

(d) precisam observar a obrigatoriedade de publicação oficial dos relatórios financeiros e de execução do contrato de gestão (art. $2^{\underline{Q}}, \mathrm{I}$, " $\mathrm{f}$ "), além do dever de prestar contas que brota da própria Constituição (na redação dada pela Emenda Constitucional 19/98, vide o art. 70 da Lei Maior);

(e) devem averbar, no ato constitutivo, a hipótese de incorporação do patrimônio, em caso de extinção ou desqualificação, ao de outra organização social devidamente qualificada ou ao patrimônio público, neste último caso numa ligeira atecnia, 
porquanto os bens públicos a serem alocados devem continuar sendo públicos, devendo haver, em regra, tão-só permissão de uso, não doação dos mesmos (art. $2^{\varrho}$, I, "j"), ainda que admitida a permuta (art. 13);

(f) submetem-se à necessidade de um contrato de gestão, a ser celebrado entre Poder Público e a respectiva organização social, tendo em vista a execução das atividades mencionadas (art. $5^{\mathbf{0}}$ ), sendo mister assinalar que tal contrato deve guardar obediência aos princípios juspublicistas, inclusive moralidade e impessoalidade (art. $7^{2}$ ), assim como oferecer agasalho expresso aos critérios objetivos de avaliação de desempenho e estipulação de tetos para despesas com remuneração e vantagens de qualquer natureza, implicando desqualificação o descumprimento das disposições contidas no referido contrato (art. 16), o qual deveria integrar, desde logo, o rol dos requisitos específicos do art. $2^{\circ}$, não se justificando este descompasso temporal, seja por razões operacionais, seja por razões estratégicas. Observe-se, antes de ir além, que a dispensa do certame licitatório (a teor da Lei 9.648/98, art.24, XXIV), somente ocorrerá se as organizações sociais estiverem desempenhando atividades contempladas no contrato público de gestão;

(g) desfrutam da possibilidade de destinação de recursos orçamentários e bens públicos imprescindíveis ao cumprimento do contrato de gestão (art. $12, \S 1^{\mathrm{Q}}$ ), bem como a cedência especial de servidor público com ônus para a origem (art. 14), o que as força a prestar as referidas satisfações ao Tribunal de Contas.

Pois bem, em face dos traços extraídos da Lei 9.637/98, resta claro que o regime de tais pessoas jurídicas de direito privado é mesmo atípico. Em minha ótica, há uma dominância de regras de direito privado e simultânea preponderância de princípios de direito público, uma vez que se encontram imantadas pelas suas próprias e inescapáveis finalidades de cogentes matizes sociais.

Certo está, como assinalado, que este regime peculiar não o é em escala bastante para que se as considerem partes inerentes à estrutura formal da Administração Pública. Pertencem - convém reiterar - ao chamado terceiro setor, contudo a elas se aplica, por exemplo, a legislação de combate à improbidade administrativa, sempre que, de algum modo, houver uso indevido dos recursos públicos (Lei 8.429/92). Da mesma sorte, a responsabilidade por danos causados por estas entidades, dado que se constituem pessoas jurídicas prestadoras de serviços de relevância social, em acepção ampla (estaríamos diante de um serviço privado de interesse público, como sugere Paulo Modesto in "Reforma Administrativa e marco legal das organizações sociais no Brasil: as dúvidas dos juristas sobre o modelo das organizações sociais" in Revista do Serviço Público, número 2, 1997, p.42), também haverá de receber o influxo parcial da regência publicista.

Além disso, esta parceria qualificada bem deve ser vista como devendo acatar princípios publicistas por duas razões superlativas: primeira, o contrato de gestão, no reconhecimento do próprio legislador infraconstitucional, precisa ser elaborado em consonância com os princípios da impessoalidade, da moralidade, da publicidade, da economicidade, entre outros (vide o art. $7^{\mathbf{9}}$ ). Ademais: a organização social deverá obedecer, na contratação de obras e serviços, bem como para compras com emprego de recursos oriundos do Poder Público, uma regulamentação (nos termos do art. 17), certamente em conformidade com os mesmos princípios. Vai daí que seja misto o 
regime das organizações sociais, porquanto, no plano das regras, revela-se dominantemente de direito privado, mas, no plano mais alto das diretrizes do sistema, a superioridade pertence aos princípios juspublicistas.

Assim caracterizado o regime, merece menção que o novel instituto comporta riscos de utilização indevida se se prestar a um processo de privatização mais ou menos dissimulada. Senão vejamos: as entidades qualificadas como organizações sociais são declaradas de interesse social e utilidade pública, para todos os efeitos, embora apresentem nuances adicionais e singularizantes (v.g., a possibilidade de aproveitamento, sem ônus, de servidores ou empregados públicos e de bens estatais), que lhes habilitam, na prática, a assumir as funções desempenhadas pelas entidades federais extintas por lei específica, v.g., no âmbito da saúde (art. 18) ou as atividades de rádio e televisão (art. 19), dentro do mencionado paradoxal programa de "publicização" (criado, aliás, por mero decreto), que visa a assegurar a referida absorção de atividades desenvolvidas por entidades ou órgãos públicos (art. 20). Diferentemente e ao revés, a "publicização", na perspectiva que advogo, nada mais deveria significar do que o alerta para que estas ONGs guardem observância ainda maior às normas de ordem pública no cotejo com as demais integrantes do terceiro setor (a propósito, em documento do Ministério da Reforma do Estado, Caderno 2, 1998, restou dito, à p. 15: “ a desvinculação administrativa em relação ao Estado não deve ser confundida com uma privatização de entidades da administração pública. As organizações sociais não serão negócio privado, mas instituições públicas que atuam fora da Administração Pública para melhor se aproximarem de suas clientelas (...). Já à p.17, o mesmo documento admite, insofismavelmente: "A implementação de organizações sociais implica duas ações complementares: a publicização de determinadas atividades executadas por entidades estatais (que serão extintas); e a absorção dessas atividades por entidades privadas qualificadas como OS, mediante contrato de gestão"). Os riscos, pois, de a publicização se converter numa privatização, efetuada sem as devidas cautelas, não são nada menosprezáveis.

De outra parte, por força da maior contribuição de recursos orçamentários e bens do Estado, convém sublinhar que maior haverá de ser o grau de comprometimento das mesmas com a obediência de requisitos específicos, bem como às cláusulas estipuladas no contrato público de gestão (definido este, nos termos do art. $5^{\circ}$, como "o instrumento firmado entre o Poder Público e a entidade qualificada como organização social, com vistas à formação de parceria entre as partes para fomento e execução de atividades relacionadas no art. $1^{0^{\prime \prime}}$ ), em cuja elaboração (reza o art. $6^{\circ}$ ), moralidade e impessoalidade, entre outros princípios administrativistas precisarão ser observados com rigor.

Destarte, não se há de admitir que a "publicização", ao contrário de induzir uma louvável complementaridade, venha a se converter numa "privatização assistida", subsidiada ou auxiliada pelo Poder Público, com cedência de pessoal, permissão de uso de bens públicos e valores, a par da remessa dos servidores para quadros em extinção, sem maior justificativa à luz do interesse público. Por tudo, se se configurar o desvirtuamento, o modelo federal poderá ter produzido um modo extremamente afrontoso de contornar exigências oriundas dos próprios princípios norteadores dos 
contratos de gestão, bem como terá ofendido regras nucleares de preservação do patrimônio público.

\section{Sugestōes para o aprimoramento do modelo federal}

No desiderato de contribuir para o aperfeiçoamento do modelo federal e, concomitantemente, sugerir formatações mais adequadas para os regimes a serem adotados no âmbito dos Estados e dos Municípios, convém sulcar as mais relevantes observações críticas à Lei $9.637 / 98$.

Como visto, no campo dos requisitos específicos, há um excesso de discricionariedade conferida ao Poder Executivo. Este "poderá" qualificar, ou não, as organizações sociais, consoante o art. 1․․ Depende, tal qualificação, de juízo favorável, quanto à conveniência, abrindo margem a discriminações arbitrárias, certamente porque o governo temia uma explosão (inocorrente) de pedidos de qualificação.

E o que é mais grave: na diç̧ão equivocada tecnicamente do art. 16, é dito que o Poder Executivo "poderá" proceder à desqualificação da entidade como organização social, quando constatado o descumprimento das disposições contidas no contrato de gestão. Aqui, mais do que nunca, verifica-se uma impropriedade técnica, pois é cogente a desqualificação, não se devendo admitir terrenos férteis a juízos subalternos ou a condescendências impertinentes.

No âmbito ainda dos requisitos específicos, merece reparo a exigência de participação, no órgão colegiado de deliberação superior, de representantes do Poder Público (art. 20, $\mathrm{I}$, “d”, nos percentuais do art. 30, I, “a”). Trata-se de regra que não deve ser reprisada nas legislações estaduais e municipais. De início, convém apontar a generalidade excessiva da norma, o que a faz operacionalmente inviabilizadora da qualificação em inúmeros casos.

Depois, bem de ver, como asseverado ao início, ao examinarmos os traços peculiares do regime, o Conselho, do qual participam os representantes do Poder Público (na composição tripartite) é que aprovará a proposta do contrato de gestão da entidade (nos termos do art. $4^{\circ}$ ), gerando uma relação perigosa e sem maiores vantagens sociais. Finalmente, convém ponderar que o terceiro setor não precisa nem deve ser "publicizado" por este tipo de ingerência para que seja efetivamente controlado pela sociedade (diretamente ou através dos mecanismos institucionais vigentes).

Outra crítica deve ser endereçada ao aludido descompasso temporal na celebração do contrato de gestão, que deveria ser requisito específico e restou desvinculado, em certa medida, do momento da qualificação, do qual, pelo menos, deveria ser próxima senão contemporânea. Contudo, a mais penetrante ressalva tem a a ver com o modo solto pelo qual as organizações sociais passaram a poder absorver atividades desenvolvidas por entidades públicas extintas, desfigurando a precípua natureza complementar e não-substitutiva do terceiro setor, algo que, à guisa de fortalecê-lo, suscita resistências culturais significativas e naturais.

Perante tais equívocos, resulta claro que as organizaçōes sociais precisariam se adstringir a atuar, ao menos preferencialmente, de modo complementar à ação estatal, 
remanescendo, apenas para situações marcadamente excepcionais, o agir das mesmas no espaço dantes ocupado por entidades públicas, desde que comprovadamente não possam ser mantidas na esfera pública estatal e prestem serviços em relação aos quais não se mostra conveniente (ao interesse público) o regime de execução indireta, através de concessões, permissões ou autorizações (que supõem lucratividade).

Neste diapasão, as brechas involuntárias do regime federal - repito - não devem ser subestimadas, sobremodo pelos legisladores estaduais e municipais, que, ao versarem sobre a matéria, precisam operar, na fixação dos pressupostos para a qualificação, de maneira ainda mais cautelosa e comedida do que aquela esposada pelo legislador federal.

Entretanto, tais desalinhos não são de porte a se tornarem paralisantes e, nos limites propostos, são sobrepujáveis, em larga medida, pelos benefícios do florescimento deste instituto. Com efeito, v.g., hospitais, escolas, museus e orquestras são alguns do muitíssimos casos de organizações sociais que, por certo, não substituem necessariamente, mas podem acrescentar qualidade e eficiência aos deficientes $e$ faltosos serviços públicos (essenciais, por definição).

As organizações sociais, portanto, devem existir, na peculiaridade do seu regime, como um dos vários instrumentos (não-excludentes) de concretização das inadiáveis tarefas socialmente relevantes, sob a forma de associações civis ou de fundações privadas (no bojo do terceiro setor) aptas a, com certo desembaraço, oferecer aporte inestimável em áreas tragicamente carentes, assim como se constata no setor de saúde. Decerto, devem receber, na estrita medida de suas necessidades, o auxílio público, tão-somente à proporção em que se mostrarem fiéis ao resguardo, em forte sentido, dos princípios administrativos, no seio destas "esferas públicas autônomas" (na expressão de Habermas in Direito e Democracia, Tempo Brasileiro, RJ, 1997, p. 186). Em outras palavras, entre os riscos e os benefícios, apesar das ressalvas feitas à Lei federal, compensam os méritos do instituto, residindo o maior dos quais na ocasião de fazer com que o Poder Público, titular da prestação de serviços públicos, admita mais uma modalidade de execução indireta dos serviços de utilidade pública ("in casu", através da atuação de parceiros qualificados ou, como parece melhor dizer, de uma aliança coobrigante sem finalidade lucrativa, à diferença do que sucede, por exemplo, nas concessōes.

E mais: a sociedade, ela mesma, assume, nas suas mãos (não raro dispostas a gestos de extrema e belíssima solidariedade anônima), a meta de sobrepassar desassistências crônicas, avançando no sentido da maioridade-cidadã, um dos vetores máximos na fundamentação do Estado em novas e promissoras bases.

\section{As principais conclusões}

Do exposto, destacam-se estas como sendo as principais conclusões:

(I) As organizações sociais podem ser extremamente benfazejas, se representarem, no plano concreto, um mecanismo complementar de atuação da sociedade civil na consecução, sem finalidade lucrativa, de tarefas de interesse social, perfeitamente catalogáveis como serviço público "lato sensu" ou de relevância pública. 
(II) Já pela natureza dos serviços prestados, já pela intensa colaboração do Poder Público no desenvolvimento das atividades encetadas por tais organizações, estas pessoas jurídicas de direito privado, precisam obedecer, de modo precípuo, princípios de ordem pública, donde dimanam as diretrizes relacionadas ao controle social de suas ações de modo transparente.

(III) Os vários mecanismos de controle não devem descurar que, a despeito da letra da lei, inexiste discricionariedade, sobremodo em matéria de desqualificação, com todos os consectários (art. 16), sendo de não manter, no plano dos Estados e Municípios, a exigência de aprovação "política", para efeitos de qualificação, por temerariamente aberta a juízos descoincidentes com o interesse público.

(IV) É forçoso, não obstante a busca, ao máximo, de reciprocidade e de harmonização legislativa, um maior rigor na disciplina dos pressupostos de tais organizações na seara dos Municípios e Estados, ao mesmo tempo que se deve, na órbita federal, cogitar de uma aproximação normativa maior, em termos de regime, com as demais organizações da sociedade civil de relevo público.

(V) Indispensável se revela que a absorção das atividades de entidades públicas extintas não se converta numa espécie de privatização sem as cautelas obrigatórias, ou seja, numa espécie de "publicização" destinada, devendo a mesma ser entendida tão-só como ênfase do caráter predominantemente publicista do regime destas pessoas componentes do terceiro setor.

(VI) A ênfase proclamada no cidadão-cliente (art. 20 da Lei $9.637 / 98$ ) bem demonstra que o legislador reconhece que tais organizações devem estrita observância a dispositivos de ordem pública, entre os quais os que cuidam da proteção do consumidor, cumprindo, no atinente à responsabilidade, ser recordada, em sua ampla gama de efeitos, a condição de prestadora de serviços públicos relevantes.

(VII) O regime das organizações sociais deveria deixar mais nítida a vinculação a regras como as relativas à probidade administrativa, sem embargo de se buscar, de "lege ferenda", em vários outros aspectos, um entrosamento mais produtivo entre Poder Público e o terceiro setor, que se apresenta como uma das mais fecundas possibilidades de mobilização das melhores energias da sociedade, aquelas forças anímicas que mantém vivas e consistentes as nossas esperanças de viabilizar uma "terceira via", que não afaste o Estado de seu papel interventivo, tampouco reduza o cidadão a espectador de uma guerra globalizada de todos contra todos: um Estado que mereça, processual e substancialmente, o qualificativo "democrático", mercê de um respeito às exigências decorrentes da própria maioridade cívica. 